\title{
Omega-3 fatty acid blood levels are inversely associated with cardiometabolic riskfactors in HFpEF patients
}

\section{Katharina Lechner ( $\nabla$ contact@katharinalechner.net)}

Kardiologie, Deutsches Herzzentrum München, Munich, Germany

Johannes Scherr

University Center for Prevention and Sports Medicine, Balgrist University Hospital, University of Zurich,

Switzerland

\section{Elke Lorenz}

Kardiologie, Deutsches Herzzentrum München, Munich, Germany

\section{Benjamin Lechner}

Department of Internal Medicine IV, Ludwig-Maximilians University, Munich, Germany

\section{Bernhard Haller}

Institute of Medical Informatics, Statistics and Epidemiology, Klinikum rechts der Isar, Technische Universität München, Munich, Germany

\section{Martin Halle}

Technical University of Munich, School of Medicine, Department of Prevention, Rehabilitation and Sports Medicine, Munich, Germany

\section{Rolf Wachter}

Clinic and Policlinic for Cardiology, University Hospital Leipzig, Leipzig, Germany

\section{André Duvinage}

Technical University of Munich, School of Medicine, Department of Prevention, Rehabilitation and Sports Medicine, Munich, Germany

\section{Frank Edelmann}

Department of Cardiology, Charité, Universitätsmedizin Berlin, Berlin, Germany

\section{Research Article}

Keywords: Omega-3 fatty acids, omega-3 index, eicosapentaenoic acid, docosahexaenoic acid, heart failure, HFpEF, diastolic dysfunction, metabolic phenotype, atherogenic dyslipidemia

Posted Date: May 25th, 2021

DOl: https://doi.org/10.21203/rs.3.rs-551004/v1 
License: (c) (i) This work is licensed under a Creative Commons Attribution 4.0 International License. Read Full License 


\section{Omega-3 fatty acid blood levels are inversely associated with cardiometabolic risk factors in HFpEF patients}

\section{Short Running Head: Omega-3 FA and cardiometabolic phenotype in HFpEF}

Katharina Lechner ${ }^{1,2,3}$, Johannes Scherr ${ }^{1,4}$, Elke Lorenz ${ }^{3}$, Benjamin Lechner ${ }^{5}$, Bernhard Haller ${ }^{6}$, Martin Halle $^{1,2}$, Rolf Wachter ${ }^{7,8}$, André Duvinage ${ }^{1,2 *}$, Frank Edelmann ${ }^{9 *}$

\section{Affiliations:}

${ }^{1}$ Technical University of Munich, School of Medicine, Department of Prevention, Rehabilitation and Sports Medicine, Munich, Germany

${ }^{2}$ DZHK (German Centre for Cardiovascular Research), Partner site Munich, Munich Heart Alliance, Munich, Germany

${ }^{3}$ Kardiologie, Deutsches Herzzentrum München, Munich, Germany

${ }^{4}$ University Center for Prevention and Sports Medicine, Balgrist University Hospital, University of Zurich, Switzerland

${ }^{5}$ Department of Internal Medicine IV, Ludwig-Maximilians University, Munich, Germany

${ }^{6}$ Institute of Medical Informatics, Statistics and Epidemiology, Klinikum rechts der Isar, Technische Universität München, Munich, Germany

${ }^{7}$ Clinic and Policlinic for Cardiology, University Hospital Leipzig, Leipzig, Germany

${ }^{8}$ University Medical Center Göttingen, Department of Cardiology and Pneumology, Georg-August University, Göttingen, Germany

${ }^{9}$ Department of Cardiology, Charité, Universitätsmedizin Berlin, Berlin, Germany

*equal contribution 


\section{Corresponding author:}

Prof. Dr. med. Frank Edelmann

Department of Cardiology, Campus Virchow Klinikum (CVK), Charité Universitätsmedizin Berlin Augustenburger Platz 1 · 13353 Berlin, Germany

Phone: +49 (0)30 $450553731 \cdot$ Fax: +49 (0)30 $4507553731 \cdot E-m a i l:$ frank.edelmann@charite.de

Word count: 3297 including references

Word count Abstract: 250 (max. 250)

Figures and Tables: 4 figures and 2 tables

Supplementary material: 3 tables 


\section{Acknowledgements}

We are indebted to the German Foundation of Heart Research (Deutsche Herzstiftung), to the AldoDHF investigators, and to the patients of the Aldo-DHF study. The sponsor had no role in the study design, data analysis and interpretation or in the decision to submit the manuscript for publication. The corresponding author had full access to all the data in the study and had final responsibility for the decision to submit for publication.

\section{Funding}

This work was supported by the German Foundation of Heart Research [F/19/18]. Aldo-DHF was funded by the Federal Ministry of Education and Research grant 01GI0205 [clinical trial program Aldo-DHF (FKZ 01KG0506)].

\section{Conflict of Interest}

$\mathrm{KL}, \mathrm{JS}, \mathrm{EL}, \mathrm{BL}, \mathrm{BH}, \mathrm{MH}, \mathrm{RW}, \mathrm{AD}, \mathrm{FE}$ declare that they have no conflict of interest to disclose with respect to this manuscript.

\section{Authors' Contributions}

All authors contributed to this manuscript. KL and AD conceptualized and designed this analysis. KL did the literature search, and drafted the manuscript. JS, EL, BL, MH, RW, and AD, critically revised and edited the manuscript. FE supervised the writing process and had major contributions. BH assisted with statistical analysis of data. All gave final approval and agree to be accountable for all aspects of their work ensuring integrity and accuracy. 


\begin{abstract}
Objectives:

To evaluate the association of Omega-3 fatty-acid (O3-FA) blood levels with cardiometabolic risk markers, functional capacity and cardiac function/morphology in HFpEF patients.
\end{abstract}

\title{
$\underline{\text { Background: }}$
}

O3-FA demonstrated favorable effects on heart failure and associated phenotypic traits in experimental/clinical studies. In patients with heart failure with preserved ejection fraction (HFpEF), the association of O3-FA status with patient characteristics is unknown.

\section{Methods:}

This is a cross-sectional analysis of baseline data from the Aldo-DHF-RCT. From 422 patients, the omega-3-index $(\mathrm{O} 3 \mathrm{I}=\mathrm{EPA}+\mathrm{DHA})$ was analyzed in $\mathrm{n}=404$ using the HS-Omega-3-Index ${ }^{\circledR}$ methodology. Patient characteristics were; $67 \pm 8$ years, 53\% female, NYHA II/III (87/13\%), ejection fraction $\geq 50 \%$, E/e' 7.1 \pm 1.5 ; median NT-proBNP $158 \mathrm{ng} / \mathrm{L}$ (IQR 82-298). Pearson's correlation coefficient was used to describe associations of the O3I with metabolic phenotype, exercise capacity, echocardiographic markers for LVDF, and neurohumoral activation.

Results:

The O3I was below $(<8 \%) /$ within( $(8-11 \%) /$ higher $>11 \%)$ than the target range in $374(93 \%) / 29(7 \%) / 1$ $(0.2 \%)$ patients respectively. Mean O3I was $5.7 \pm 1.7 \%$. The O3I was inversely associated with HbA1c $(\mathrm{r}=-0.139, \mathrm{p}=0.006)$, triglycerides-to-HDL-C ratio $(\mathrm{r}=-0.12, \mathrm{p}=0.017)$, triglycerides $(\mathrm{r}=-0.117, \mathrm{p}=0.02)$, non-HDL-C $(r=-0.101, p=0.044)$, body-mass-index $(r=-0.149, p=0.003)$, waist circumference $(r=-$ $0.121, \mathrm{p}=0.015)$, waist-to-height ratio $(\mathrm{r}=-0.141, \mathrm{p}=0.005)$, and positively associated with submaximal aerobic capacity $(\mathrm{r}=0.113, \mathrm{p}=0.023)$ and LVEF $(\mathrm{r}=0.211, \mathrm{p}<0.001)$. We did not observe an association between the $=3$ I and maximal functional capacity, echocardiographic markers of LVDF or NTproBNP.

\section{Conclusions:}


Higher O3I was associated with a more favorable cardiometabolic risk profile and better submaximal aerobic capacity in HFpEF patients but did not correlate with echocardiographic markers for left ventricular filling pressures, left ventricular relaxation or neurohumoral activation.

\section{Key Words}

Omega-3 fatty acids, omega-3 index, eicosapentaenoic acid, docosahexaenoic acid, heart failure, HFpEF, diastolic dysfunction, metabolic phenotype, atherogenic dyslipidemia

\section{Central Illustration}

Omega-3 Index and HFpEF Patient Characteristics

\section{One sentence summary}

Higher omega-3 fatty acid blood levels are associated with a more favorable cardiometabolic risk profile and higher submaximal aerobic capacity in patients with HFpEF.

\section{Condensed Abstract}

We evaluated omega-3 fatty-acid (O3-FA) blood levels in patients with HFpEF from the Aldo-DHF trial to assess associations with cardiometabolic risk markers, functional capacity and cardiac function/morphology. Higher O3-FA blood levels were broadly associated with a more favorable cardiometabolic risk profile and better submaximal aerobic capacity in HFpEF patients but did not correlate with echocardiographic markers for left ventricular filling pressures, left ventricular relaxation or neurohumoral activation. 


\section{Introduction}

The prevalence of heart failure (HF) with preserved ejection fraction (HFpEF) relative to heart failure with reduced ejection fraction (HFrEF) continues to increase. [1] HFpEF has similar mortality to HFrEF, however, standard pharmacological therapies as applied in HFrEF have failed to show prognostic impact in HFpEF. [2,3] The rising prevalence of HFpEF and the absence of established pharmacological treatment options result in individual suffering and socioeconomic burden. [3]

HFpEF clinically presents as a heterogeneous condition with numerous underlying aetiologies [4] but conceptually relates to a distinct metabolic phenotype characterized by extracardiac comorbidities such as obesity, arterial hypertension (HT), and type 2 diabetes mellitus (T2D). [1] A unifying hallmark of these metabolic features is the accumulation of ectopic adipose tissue in the epicardium. [5] The latter drives left ventricular remodeling and dysfunction through altered paracrine signaling to cardiomyocytes, through macrophage infiltration, and interstitial fibrosis and through systemic inflammation and coronary microvascular endothelial dysfunction. [1,2]

The two long-chain omega-3 fatty acids (O3-FA) eicosapentaenoic acid (EPA; C20:5n3) and/or docosahexaenoic acid (DHA; C22:6n3) have been shown to reduce blood pressure, biomarkers of myocardial fibrosis such as ST2, ameliorate left ventricular diastolic function, and decrease markers of natriuretic peptide system activation and wall stress like brain natriuretic peptide (BNP) in HF patients. [6-8] Biologic properties of EPA\&DHA provide plausibility for these effects; they are antiinflammatory, [9,10] improve vascular endothelial function, [11] decrease systolic/diastolic blood pressure, [12], decrease resting heart rate, [12], increase heart rate variability, [13,14], have antiarrhythmic properties, [15], and decrease cardiac remodeling. [7] In part mediated by these effects, O3-FA may impact on cardiomeabolic phenotype in HFpEF. [16] In HFrEF, O3-FA have been endorsed as a safe treatment option on top of guideline-based usual care with a Class IIa and Class IIb recommendation by the AHA [17] and ESC [2] respectively.

As measured, the effects of EPA\&DHA correlate with the omega-3 index (O3I), a biomarker for tissue O3-FA status $[7,18]$ which is unbiased by recent dietary intake and reliably reflects long-term cardiac and other tissue EPA\&DHA levels in the absence and presence of supplementation. $[19,20]$ The O3I 
tracks more closely with clinical endpoints than dietary intake, as has been consistently demonstrated in intervention and observational studies. [7,21,22]

The association between EPA\&DHA tissue levels and patient characteristics in HFpEF is not known. To fill this gap, we report the O3I in a large cohort comprised of $404 \mathrm{HFpEF}$ patients from the Aldosterone in Diastolic Heart Failure (Aldo-DHF) trial and associations with metabolic phenotype, exercise capacity, echocardiographic markers indicative of left ventricular diastolic function (LVDF), and neurohumoral activation. We hypothesized that the O3I would correlate inversely with biomarkers indicative of cardiometabolic risk, LVDF, and neurohumoral activation in patients with HFpEF.

\section{Methods}

\section{$\underline{\text { Study Design }}$}

This is a post-hoc analysis of the Aldo-DHF trial (ISRCTN 94726526). We analyzed O3-FA blood cell membrane levels at baseline. From a total of 422 patients enrolled in the Aldo-DHF trial, 18 whole blood aliquots were not available due to loss during storage/transfer or missing blood sampling at baseline. Baseline characteristics are depicted in Table 1.

\section{The Aldo-DHF Trial}

The Aldo-DHF trial is a multicenter, prospective, randomized, double-blind, placebo-controlled trial evaluating the effect of a 12 months aldosterone receptor blockade on diastolic function (E/e') on echocardiography and maximal exercise capacity (peak $\mathrm{V}^{\cdot} \mathrm{O} 2$ ) in $\mathrm{HFpEF}$ patients. Men and women aged 50 years or older were eligible to participate in the study if they had current HF symptoms consistent with New York Heart Association (NYHA) class II or III, left ventricular ejection fraction (LVEF) of 50\% or greater, echocardiographic evidence of diastolic dysfunction (grade I) or atrial fibrillation at presentation, and maximum exercise capacity (peakV ${ }^{\cdot}$ O2) of $25 \mathrm{~mL} / \mathrm{kg} / \mathrm{min}$ or less.[23] 422 ambulatory patients (mean age 67 [SD, 8] years; 52\% female) with chronic NYHA class II or III heart failure, preserved left ventricular ejection fraction (LVEF) of $50 \%$ or greater, and evidence of diastolic dysfunction were included. Data acquisition was conducted between March 2007 and April 2012 at 10 sites in Germany and Austria. [23] 


\section{Laboratory measurements}

\section{Laboratory Methods: Aldo-DHF Trial}

Venous blood samples were drawn under standardized conditions after 20 minutes of rest in supine position. Samples were immediately cooled, centrifuged, and processed for storage at $-80^{\circ} \mathrm{C}\left(-112^{\circ} \mathrm{F}\right)$. N-terminal pro-brain-type natriuretic peptide (NT-proBNP) was analyzed with the Elecsys NTproBNP immunoassay (Roche Diagnostics). [23]

\section{Laboratory methods: HS-Omega-3 Index ${ }^{\circledR}$ methodology}

Blood samples from the Aldo-DHF trial were immediately stored at $-80^{\circ} \mathrm{C}$. This results in stable $\mathrm{O} 3$ levels.[24] For analysis of fatty acid composition, $2.0 \mathrm{~mL}$ aliquots of frozen $\left(-80^{\circ} \mathrm{C}\right)$ EDTA-blood were sent to Omegametrix (Martinsried, Germany). At Omegametrix, a reference laboratory for fatty acid analyses, whole blood fatty acid composition was analyzed according to the HS-Omega-3 Index ${ }^{\circledR}$ methodology.[25] Fatty acid methyl esters were generated by acid transesterification and were analyzed by gas chromatography using a GC2010 Gas Chromatograph (Shimadzu, Duisburg, Germany) equipped with a SP2560, 100-m column (Supelco, Bellefonte, Pennsylvania, United States) using hydrogen as carrier gas. Fatty acids were identified by comparison with a standard mixture of fatty acids characteristic of erythrocytes. Results for EPA\&DHA from whole blood aliquots were recalculated into the erythrocyte O3I by the use of a validated correction factor,[25] while individual fatty acid results are given as relative amounts of ALA (C18:3n3), EPA (C20:5n3) and DHA (C22:6n3) expressed as a percentage of a total of 26 identified FAs in whole blood. Analyses were quality-controlled according to DIN ISO 15189.

\section{Echocardiography and other variables}

In the Aldo-DHF Trial, clinical data were obtained and diagnostic procedures were done according to pre-defined standard operating procedures based on international guidelines. [23] Diastolic function on echocardiography was assessed in accordance with American Society of Echocardiography guidelines. [26] 


\section{Ethics}

The Aldo-DHF Trial complies with the Declaration of Helsinki and principles of good clinical practice. All responsible ethics committees approved the study protocol. All participants gave written informed consent.

\section{$\underline{\text { Statistical analysis }}$}

Continuous variables are reported as mean $+/$-standard deviation (SD) or median [interquartile range (IQR)], according to normality of distribution. Discrete variables are presented as absolute and relative frequencies. Bivariate correlations were assessed by Pearson's correlation coefficient (r) to evaluate associations of the O3I/prespecified O3-FA (ALA, EPA, DHA) with cardiometabolic risk markers, echocardiographic markers of LVDF and neurohumoral activation. Partial correlations adjusting for heart failure medication (ACE-inhibitors, AT1-antagonists, betablockers, thiazide-diuretics, loopdiuretics, aldosterone-antagonists, other diuretics, calcium-channel-blockers), systolic and diastolic blood pressure (BP), and $\mathrm{HbAlc}$ were estimated. Independent samples t-test was used to compare E/e' of the groups with an $\mathrm{O} 3 \mathrm{I}<4 \%$ and an $\mathrm{O} 3 \mathrm{I}>8 \%$. These indices represent clinically established cut-offs for deficiency and optimal O3 status respectively. A significance level of $\alpha=5 \%$ was used for all tests. Considering our cohort of 404 patients, the probability (=power) of detecting an association between two statistical variables was $85 \%$ assuming a true correlation of $r=0.15$. All statistical analyses were performed using IBM SPSS Statistics for Windows, version 25 (IBM Corp., Armonk, N.Y., USA).

\section{Results}

\section{$\underline{\text { Study Population }}$}

Baseline characteristics are shown in Table 1. Mean O3I at baseline was 5.7 $1.7 \%$ (minimum 2.19\%; maximum 12.11\%) as depicted in Figure 1. The O3I was below $(<8 \%)$, within $(8-11 \%)$, or higher $(>11 \%)$ than the target range in in $374(93 \%), 29(7 \%)$ and in $1(0.2 \%)$ patients respectively.

\section{O3I and LVEF}

O3I, EPA, and DHA showed a positive association with LVEF $(r=0.211, p<0.001 ; r=0.123, p=0.013$, and $\mathrm{r}=0.226, \mathrm{p}=<0.001$, respectively) as shown in Figure 2 and Supplementary Table 1. 


\section{$\underline{\text { O3I and metabolic phenotype }}$}

Higher O3I was broadly associated with a more favorable cardiometabolic risk profile as depicted in

Multipanel Figure 3 (A-G) and Table 2. The O3I was inversely associated with $\mathrm{HbA1c}(\mathrm{r}=-0.139$, $\mathrm{p}=0.006), \mathrm{TG} /$ HDL-C ratio $(\mathrm{r}=-0.12, \mathrm{p}=0.017)$, triglycerides $(\mathrm{r}=-0.117, \mathrm{p}=0.02)$, non-HDL-C $(\mathrm{r}=-$ 0.101, $\mathrm{p}=0.044)$, BMI $(\mathrm{r}=-0.149, \mathrm{p}=0.003)$, waist circumference $(\mathrm{WC})(\mathrm{r}=-0.121, \mathrm{p}=0.015)$, waist-toheight ratio $(\mathrm{WHtR})(\mathrm{r}=-0.141, \mathrm{p}=0.005)$ and $\mathrm{GGT}(\mathrm{r}=-0.125, \mathrm{p}=0.012)$.

No association was found between the O3I and BP under medication [( systolic $(r=-0.022, p=0.663)$, diastolic $(\mathrm{r}=-0.097, \mathrm{p}=0.052)]$, heart rate $(\mathrm{HR})$ under medication $(\mathrm{r}=-0.085, \mathrm{p}=0.087)$, HDL-C $(\mathrm{r}=0.039, \mathrm{p}=0.435), \mathrm{LDL}-\mathrm{C}(\mathrm{r}=-0.035, \mathrm{p}=0.487)$, and transaminases [(ASAT $(\mathrm{r}=-0.053, \mathrm{p}=0.288)$, $\operatorname{ALAT}(\mathrm{r}=-0.084, \mathrm{p}=0.591)]$.

\section{O3I and Functional Capacity}

O3I was associated with a higher distance covered $(\mathrm{r}=0.113, \mathrm{p}=0.023)$, and lower maximal diastolic BP during the six-minute walk test (6 MWT) $(r=-0.138, p=0.006)$ as depicted in Multipanel Figure 4 (A-B) and Supplementary Table 2. No association was found with maximal aerobic capacity (peak $\mathrm{VO} 2(\mathrm{r}=-0.005, \mathrm{p}=0.919)$.

\section{O3I and LVDF}

The O3I showed no correlation with markers for left ventricular relaxation or other surrogates for LVDF: E/A ratio $(r=-0.031, p=0.55)$, deceleration time $(r=0.019, p=0.70), E / e^{\prime}(r=-0.029, p=0.56)$, and left atrial volume index (LAVI) $(\mathrm{r}=-0.029, \mathrm{p}=0.571)$. Using logarithmic transformation, the association of the O3I and neurohumoral activation (NT-proBNP) was not significant $(\mathrm{r}=0.062, \mathrm{p}=0.221)$.

Partial correlations adjusting for heart failure medication and $\mathrm{HbAlc}$ did not alter our results.

The comparison of E/e' in an $\mathrm{O} 3$ deficient versus $\mathrm{O} 3$ sufficient group (i.e., an $\mathrm{O} 3 \mathrm{I}<4 \%$ ( $\mathrm{n}=64$ ) vs an O3I $>8 \%(\mathrm{n}=30) ;(\mathrm{t}(92)=0.61, \mathrm{p}=0.54))$ showed no statistically significant difference.

\section{Association between individual O3-FA and LVDF}

The plant derived alpha-linolenic acid (ALA; C18:3n3) was very weakly $(r=0.184, p<0.001)$ and 
EPA, DHA, or the O3I $(r=0.096, p=0.057$ and $r=0.042, p=0.407)$ showed no significant correlation with levels of NTproBNP. We did not observe a significant association between ALA, EPA, and DHA and echocardiographic measures of LVDF. Adjusting for heart failure medication, systolic and diastolic blood pressure, and HbA1c did not alter our results. All correlations coefficients of the O3I and individual FAs (ALA, EPA, DHA) with LVDF and neurohumoral activation are depicted in

\section{Supplementary Table 3.}

\section{Discussion}

This analysis shows omega-3 status in HFpEF patients and associations with cardiometabolic risk factors, exercise capacity, echocardiographic markers of left ventricular diastolic function, and neurohumoral activation. (Central Illustration)

\section{LVEF, LV-mass, and the O3I}

Epidemiological and experimental studies as well as post hoc analyses of randomized controlled trials (RCT) suggest that O3-FA are beneficial in chronic HF. In the Cardiovascular Health Study, higher circulating individual and total O3-FA concentrations correlated with a lower incidence of congestive HF in 2735 adults without heart disease.[27] Similarly, two double-blind, placebo-controlled, RCT showed that in 6975 and 4574 patients with HF, O3-FA (1g/d), but not rosuvastatin $(10 \mathrm{mg} / \mathrm{d})$, significantly decreased the two coprimary end points (death, and death or admission to hospital for cardiovascular reasons). [28] Another study provided a small benefit regarding supplementation with 1 g O3-FA in terms of mortality and hospital admissions in patients with HF. [29] In patients with acute myocardial infarction (MI), treatment with high-dose O3-FA was associated with a reduction of adverse left ventricular remodeling, noninfarct myocardial fibrosis (ST2), and serum biomarkers of systemic and vascular inflammation (MPO, Lp-PLA2). [7] For these reasons, treatment with O3-FA has been endorsed for treatment of HFrEF with a Class IIa and Class IIb recommendation by the AHA [17] and ESC [2] respectively. In line, our data suggest a positive but weak correlation of LVEF with the O3I, EPA and DHA.

Metabolic Phenotype and the O3I

$\underline{\text { Lipid Metabolism }}$ 
Mechanistically, O3-FA interfere with hepatic lipid metabolism by downregulating genes involved in de-novo lipogenesis (DNL), and thus deplete the hepatic pool of triglycerides. [15] Accordingly, high intakes of EPA\&DHA have been demonstrated to reduce the expression of atherogenic dyslipidaemia. For example, O3-FA ( $>1 \mathrm{~g}$ for at least 3 months) modulate particle distribution, phenotype and lipidome by reducing ApoB46 and ApoC3 [15,30] and triglycerides [31] in patients with MetS. In concordance with these findings, we observed an inverse correlation of triglycerides, TG/HDL-C ratio, and non-HDL-C with the O3I. A higher TG/HDL-C ratio is associated with higher levels of remnant lipoprotein particle cholesterol, non-HDL-C and LDL density, reflecting an atherogenic lipid phenotype [32], and a higher risk plaque phenotype (thin-cap fibroatheroma) in patients with coronary artery disease. [33-35] Triglycerides show a causal and dose dependent association with ASCVD risk. [36] Collectively, this provides confidence that our findings indicate that a higher O3I is associated with a lower risk lipoprotein pattern. As expected, no inverse association was found between the O3I and LDL-C, which aligns with prior RCTs, where therapeutic doses of O3-FA (3g/day) were associated with increases in LDL-C in patients with MetS [31] or had no effect on LDL-C in patients with nonalcoholic fatty liver disease (NAFLD). [37] Of note, in the subgroup of patients with MetS, non-HDL-C is superior to LDL-C as a risk indicator for atherosclerotic cardiovascular disease risk.

\section{Glucose metabolism}

While O3-FA in therapeutic doses are recommended for managing hypertriglyceridemia,[36] data on their impact on glucose metabolism are inconclusive. The majority of observational studies show an inverse association between O3-FA and insulin resistance. [40] Most human intervention studies and meta-analyses of RCTs failed to demonstrate a benefit of O3-FA in individuals living with insulin resistance or T2D. [40,41] The tight pathophysiological link between NAFLD, hypertriglyceridemia and insulin resistance/T2D might offer biological plausibility for our finding of an inverse association of the O3I with blood glucose.

$\underline{\text { Surrogate markers for NAFLD }}$ 
EPA\&DHA influence hepatic triglyceride pool and lipoprotein metabolism by the following mechanisms: first they promote hepatic fatty acid oxidation by interfering with the PPAR (peroxisome proliferator-activated receptors) system, especially PPAR $\alpha$ and second, they downregulate the expression of the two lipogenic transcription factors SREBP-1C and ChREBP. [42] In preclinical models, EPA\&DHA are associated with anti-inflammatory and antisteatotic effects[43]. In humans, a meta-analysis on the effect of O3-FA supplementation (2-5 g per day) in patients with NAFLD or nonalcoholic steatohepatitis (NASH) in part replicated these results. O3-FA lowered liver fat content, and gamma-glutamyltransferase (GGT) levels but had no effect on alanine aminotransferase (ALT) and aspartate aminotransferase (AST) in patients with NAFLD/NASH.[37] Replicating these results, we observed an inverse association of the O3I with GGT, but not with transaminases.

BMI and anthropometric markers of truncal adiposity

BMI is inconsistently associated with outcomes, particularly in heart failure (i.e., obesity parardox). $[44,45]$ Contrarily, anthropometric markers indicative of visceral adiposity such as WC [46] and WHtR $[47,48]$ are more reliable indicators of insulin resistance, adipose tissue distribution, cardiometabolic risk and/or high risk atherosclerosis. [39] We observed an inverse correlation of BMI, WC and WHtR with the O3I, indicating that in HFpEF patients, a higher omega-3 tissue status is associated with a lower risk metabolic phenotype.

\section{Blood pressure and heart rate}

Epidemiological data in normotensive young, healthy individuals showed a significant and clinically relevant inverse association of the O3I with systolic and diastolic BP. [18] This is in line meta-analytic evidence of RCTs that showed that EPA\&DHA containing supplements decreased systolic/diastolic BP and HR. [12] As reported in Table 1, the vast majority of our patients were on anti-hypertensive medication and betablockers, likely to preclude us from confirming the inverse correlation between $\mathrm{BP} / \mathrm{HR}$ and the O3I. [12,18]

\section{Functional capacity and the $\mathrm{O} 3 \mathrm{I}$}

The O3I was associated with a higher distance covered and with a lower maximal diastolic BP during the 6MWT, reflecting better submaximal aerobic capacity, but was not associated with maximal 
aerobic capacity. Data on the effect of O3-FA supplementation on exercise performance with regard to strength and anaerobic capacity in athletes are conflicting [49] but no such data have been generated in HF patients to the best of our knowledge.

\section{Neurohumoral Activation and O3I}

We did not observe a significant association of NT-proBNP with the O3I or EPA\&DHA. However, natriuretic peptides are used as an adjunct to identify severe, but not moderate or mild diastolic function. [50] This cohort depicts early stage HFpEF and the median NT-proBNP plasma level in Aldo-DHF (158 ng/L) was higher than in healthy age-matched controls [51] but lower than in previous analyses of HFpEF patients such as I-PRESERVE. [52]

\section{Echocardiographic markers of LVDF and O3I}

Membrane lipid environments determine cellular functions. Incorporation of EPA\&DHA into membrane phospholipids has been reported to alter metabolic/physiochemical properties of cells/tissues such as fluidity/elasticity. [15] Tissue levels of O3-FA might thus impact on both early (energy-dependent) and late (compliance-dependent) left ventricular diastolic filling. [15] In line, a longitudinal study evaluating the effect of $4 \mathrm{~g} / \mathrm{d}$ of ethyl ester concentrates of DHA vs placebo ( $4 \mathrm{~g} / \mathrm{d}$ corn oil) on echocardiographic parameters of LVDF showed significantly improved left ventricular diastolic filling in the marine compared to the placebo group. [53] Another study evaluating the supplementation of $1 \mathrm{~g}$ omega-3 FA in 205 patients with $\mathrm{HFrEF}(\mathrm{EF}<40 \%)$ due to ischemic or dilated cardiomyopathy (NYHA I-III, EF < 40\%) showed improved LVDF after 6 months of treatment compared to placebo. [6] Further to that, a double-blind, placebo controlled, cross-over trial evaluating the effect of an 8-week supplementation of $2 \mathrm{~g} \mathrm{O}$-FA vs $2 \mathrm{~g}$ of olive oil in 31 patients with ischemic HF showed a significant improvement in LVDF on echocardiographic parameters in the marine group vs the placebo group (E/e' ratio decreased by $-9.47 \%$ vs $-2.1 \%$ ). [54] In this cross-sectional analysis, we did not observe a significant relationship of the O3I and echocardiographic and biochemical surrogates for left ventricular relaxation and left ventricular filling pressures. There are however, several limitations to consider that should provide caution against oversimplified inference when interpreting these findings. 
First, a striking difference is that prior studies have analyzed the change of echocardiographic parameters following supplementation of O3-FA longitudinally. It is thus tempting to speculate that sensitivity of echocardiographic markers might suffice for detection of changes in LVDF over time but are not appropriate for detection of inter-individual differences cross-sectionally. Consistent with this hypothesis, a prior cross-sectional analyses from the Aldo-DHF trial showed no significant association of exercise training with echocardiographic markers of diastolic function [50] whereas in the Ex-DHF pilot study, which analyzed the effect of exercise training on LVDF longitudinally, a positive effect of exercise training on diastolic function was reported. [55] Second, the spread of the O3I detected in the Aldo-DHF cohort might have been insufficient, a phenomenon that was observed earlier in another epidemiologic study. [56,57] At baseline, the average O3I was 5.7 $1.7 \%$, with values ranging from 2.19 to $12.11 \%$ as depicted in Figure 1. Only 28 patients had an index $>8 \%$. In the intervention trial that demonstrated a reduction in myocardial fibrosis with EPA\&DHA, the O3I increased from $5.5+1.8 \%$ by $81 \%$, i.e. to $10.0 \%$. (13) If an O3I of $10 \%$ were needed to reduce myocardial fibrosis in HFrEF patients, the number of patients with such values in Aldo-DHF was probably too small to produce a positive result for this parameter, which might also have been true for the other parameters assessed in our study. An O3I-driven trial in patients with HFpEF similar to the one performed by Heydari et al. [7] would probably clarify this issue. Third, despite adjustment for potential confounders, we cannot exclude the possibility of residual confounding. Furthermore, no data is available on O3-FA supplementation. Finally, the cross-sectional nature of this study design limits our ability to make a causal inference on the association of omega-3 status and LVDF. Collectively, these major limitations might justify an O3I-driven intervention trial that evaluates the effect of O3-FA supplementation on LVDF in patients with HFpEF longitudinally. (Central Illustration)

Strengths of this analysis are the large sample size comprising $404 \mathrm{HFpEF}$ patients who underwent detailed phenotypization. Furthermore, with a proportion of $53 \%$ of the patients included in Aldo-DHF being female, this analysis adequately reflects the gender distribution in HFpEF. [4] Third, O3-FA blood cell membrane levels reflect cardiac and other tissue EPA\&DHA levels in the absence and presence of supplementation with EPA\&DHA. [19,20] 


\section{Conclusion}

In patients with $\mathrm{HFpEF}$, the O3I was below the target range in 374 (93\%) patients, indicating a deficit in EPA\&DHA. Higher O3I was associated with a more favorable cardiometabolic risk profile but did not correlate with echocardiographic surrogate markers for left ventricular filling pressures, left ventricular relaxation or neurohumoral activation.

\section{Clinical Perspectives}

\section{Competency in Patient Care}

Higher O3-FA tissue levels were associated with a more favorable cardiometabolic risk profile and with higher submaximal aerobic capacity in patients with HFpEF.

\section{Translational Outlook}

Prospective clinical studies are needed to test the hypothesis that the metabolic benefits derived from O3-FA translate into prognostic benefit in patients with HFpEF and to elucidate the mechanisms involved.

\section{References}

1. Shah SJ, Kitzman DW, Borlaug BA et al. Phenotype-Specific Treatment of Heart Failure With Preserved Ejection Fraction. Circulation 2016; 134: 73

2. Ponikowski P, Voors AA, Anker SD et al. 2016 ESC Guidelines for the diagnosis and treatment of acute and chronic heart failure: The Task Force for the diagnosis and treatment of acute and chronic heart failure of the European Society of Cardiology (ESC)Developed with the special contribution of the Heart Failure Association (HFA) of the ESC. European heart journal 2016; 37: 2129-2200

3. Butler J, Fonarow GC, Zile MR et al. Developing Therapies for Heart Failure With Preserved Ejection Fraction. JACC: Heart Failure 2014; 2: 97-112

4. Pieske B, Tschöpe $C$, de Boer RA et al. How to diagnose heart failure with preserved ejection fraction: the HFA-PEFF diagnostic algorithm: a consensus recommendation from the Heart Failure Association (HFA) of the European Society of Cardiology (ESC). European heart journal 2019; 40: 3297-3317

5. Packer M. Epicardial Adipose Tissue May Mediate Deleterious Effects of Obesity and Inflammation on the Myocardium. Journal of the American College of Cardiology 2018; 71: 2360-2372

6. Chrysohoou C, Metallinos G, Georgiopoulos $\mathrm{G}$ et al. Short term omega-3 polyunsaturated fatty acid supplementation induces favorable changes in right ventricle function and diastolic filling pressure in patients with chronic heart failure; A randomized clinical trial. Vascular pharmacology 2016; 79: 43-50

7. Heydari B, Abdullah S, Pottala JV et al. Effect of Omega-3 Acid Ethyl Esters on Left Ventricular Remodeling After Acute Myocardial Infarction: The OMEGA-REMODEL Randomized Clinical Trial. Circulation 2016; 134: 378-391 
8. Sakamoto A, Saotome M, Iguchi K et al. Marine-Derived Omega-3 Polyunsaturated Fatty Acids and Heart Failure: Current Understanding for Basic to Clinical Relevance. International journal of molecular sciences 2019; 20:

9. Zampelas A, Panagiotakos DB, Pitsavos $C$ et al. Fish consumption among healthy adults is associated with decreased levels of inflammatory markers related to cardiovascular disease: the ATTICA study. Journal of the American College of Cardiology 2005; 46: 120-124

10. Bäck M, Yurdagul A, Jr., Tabas I et al. Inflammation and its resolution in atherosclerosis: mediators and therapeutic opportunities. Nature reviews Cardiology 2019; 16: 389-406

11. Wang $Q$, Liang $X$, Wang $L$ et al. Effect of omega- 3 fatty acids supplementation on endothelial function: a meta-analysis of randomized controlled trials. Atherosclerosis 2012; 221: 536-543

12. AbuMweis $S$, Jew $S$, Tayyem $R$ et al. Eicosapentaenoic acid and docosahexaenoic acid containing supplements modulate risk factors for cardiovascular disease: a meta-analysis of randomised placebo-control human clinical trials. Journal of human nutrition and dietetics : the official journal of the British Dietetic Association 2018; 31: 67-84

13. Xin W, Wei W, Li XY. Short-term effects of fish-oil supplementation on heart rate variability in humans: a meta-analysis of randomized controlled trials. The American journal of clinical nutrition 2013; 97: 926-935

14. Christensen JH. Omega-3 polyunsaturated Fatty acids and heart rate variability. Frontiers in physiology 2011; 2: 84

15. Mozaffarian D, Wu JH. Omega-3 fatty acids and cardiovascular disease: effects on risk factors, molecular pathways, and clinical events. Journal of the American College of Cardiology 2011; 58: 2047-2067

16. Lechner K, von Schacky C, McKenzie AL et al. Lifestyle factors and high-risk atherosclerosis: Pathways and mechanisms beyond traditional risk factors. European journal of preventive cardiology 2019, DOI: 10.1177/2047487319869400: 2047487319869400

17. Siscovick DS, Barringer TA, Fretts AM et al. Omega-3 Polyunsaturated Fatty Acid (Fish Oil) Supplementation and the Prevention of Clinical Cardiovascular Disease: A Science Advisory From the American Heart Association. Circulation 2017; 135: e867-e884

18. Filipovic MG, Aeschbacher S, Reiner MF et al. Whole blood omega-3 fatty acid concentrations are inversely associated with blood pressure in young, healthy adults. Journal of hypertension 2018, DOI: 10.1097/hjh.0000000000001728:

19. Harris WS, Sands SA, Windsor SL et al. Omega-3 fatty acids in cardiac biopsies from heart transplantation patients: correlation with erythrocytes and response to supplementation. Circulation 2004; 110: 1645-1649

20. Arnold C, Markovic M, Blossey K et al. Arachidonic acid-metabolizing cytochrome P450 enzymes are targets of \{omega\}-3 fatty acids. The Journal of biological chemistry 2010; 285 : 32720-32733

21. von Schacky C. Omega-3 fatty acids in cardiovascular disease--an uphill battle. Prostaglandins, leukotrienes, and essential fatty acids 2015; 92: 41-47

22. Harris WS, Tintle NL, Etherton MR et al. Erythrocyte long-chain omega-3 fatty acid levels are inversely associated with mortality and with incident cardiovascular disease: The Framingham Heart Study. Journal of clinical lipidology 2018; 12: 718-727.e716

23. Edelmann F, Wachter R, Schmidt AG et al. Effect of spironolactone on diastolic function and exercise capacity in patients with heart failure with preserved ejection fraction: the Aldo-DHF randomized controlled trial. Jama 2013; 309: 781-791

24. von Schacky C. The Omega-3 Index as a risk factor for cardiovascular diseases. Prostaglandins \& other lipid mediators 2011; 96: 94-98

25. Harris WS. The omega-3 index: clinical utility for therapeutic intervention. Current cardiology reports 2010; 12: 503-508

26. Cheitlin MD, Armstrong WF, Aurigemma GP et al. ACC/AHA/ASE 2003 guideline update for the clinical application of echocardiography: summary article: a report of the American College of Cardiology/American Heart Association Task Force on Practice Guidelines 
(ACC/AHA/ASE Committee to Update the 1997 Guidelines for the Clinical Application of Echocardiography). Circulation 2003; 108: 1146-1162

27. Mozaffarian D, Lemaitre RN, King IB et al. Circulating long-chain $\omega-3$ fatty acids and incidence of congestive heart failure in older adults: the cardiovascular health study: a cohort study. Ann Intern Med 2011; 155: 160-170

28. Marchioli R, Levantesi G, Silletta MG et al. Effect of n-3 polyunsaturated fatty acids and rosuvastatin in patients with heart failure: results of the GISSI-HF trial. Expert review of cardiovascular therapy 2009; 7: 735-748

29. Tavazzi L, Maggioni AP, Marchioli R et al. Effect of $n-3$ polyunsaturated fatty acids in patients with chronic heart failure (the GISSI-HF trial): a randomised, double-blind, placebo-controlled trial. Lancet (London, England) 2008; 372: 1223-1230

30. Dunbar RL, Nicholls SJ, Maki KC et al. Effects of omega-3 carboxylic acids on lipoprotein particles and other cardiovascular risk markers in high-risk statin-treated patients with residual hypertriglyceridemia: a randomized, controlled, double-blind trial. Lipids in health and disease 2015; 14: 98

31. Lopez-Huertas E. The effect of EPA and DHA on metabolic syndrome patients: a systematic review of randomised controlled trials. The British journal of nutrition 2012; 107 Suppl 2: S185-194

32. Quispe R, Manalac RJ, Faridi KF et al. Relationship of the triglyceride to high-density lipoprotein cholesterol (TG/HDL-C) ratio to the remainder of the lipid profile: The Very Large Database of Lipids-4 (VLDL-4) study. Atherosclerosis 2015; 242: 243-250

33. Lechner K, Halle M. Are Atherogenic Lipoprotein Phenotype and Inflammation Indicative of Plaque Phenotype and Clinical Stability in Coronary Artery Disease? JAMA Cardiology 2019; 4: 950-951

34. Vergallo R, Porto I, Crea F. Are Atherogenic Lipoprotein Phenotype and Inflammation Indicative of Plaque Phenotype and Clinical Stability in Coronary Artery Disease?-Reply. JAMA Cardiol 2019; 4: 951-952

35. Vergallo R, Porto I, D'Amario D et al. Coronary Atherosclerotic Phenotype and Plaque Healing in Patients With Recurrent Acute Coronary Syndromes Compared With Patients With Longterm Clinical Stability: An In Vivo Optical Coherence Tomography Study. JAMA Cardiol 2019; 4: $321-329$

36. Ganda OP, Bhatt DL, Mason RP et al. Unmet Need for Adjunctive Dyslipidemia Therapy in Hypertriglyceridemia Management. Journal of the American College of Cardiology 2018; 72: 330-343

37. Lu W, Li S, Li J et al. Effects of Omega-3 Fatty Acid in Nonalcoholic Fatty Liver Disease: A Meta-Analysis. Gastroenterol Res Pract 2016; 2016: 1459790

38. Mach F, Baigent C, Catapano AL et al. 2019 ESC/EAS Guidelines for the management of dyslipidaemias: lipid modification to reduce cardiovascular risk. European heart journal 2020; 41: 111-188

39. Lechner K, McKenzie AL, Kränkel N et al. High-Risk Atherosclerosis and Metabolic Phenotype: The Roles of Ectopic Adiposity, Atherogenic Dyslipidemia, and Inflammation. Metabolic syndrome and related disorders 2020; 18: 176-185

40. Lalia AZ, Lanza IR. Insulin-Sensitizing Effects of Omega-3 Fatty Acids: Lost in Translation? Nutrients 2016; 8:

41. Akinkuolie AO, Ngwa JS, Meigs JB et al. Omega-3 polyunsaturated fatty acid and insulin sensitivity: a meta-analysis of randomized controlled trials. Clinical nutrition (Edinburgh, Scotland) 2011; 30: 702-707

42. Scorletti E, Byrne CD. Omega-3 fatty acids and non-alcoholic fatty liver disease: Evidence of efficacy and mechanism of action. Molecular aspects of medicine 2018; 64: 135-146

43. Valenzuela R, Videla LA. Impact of the Co-Administration of N-3 Fatty Acids and Olive Oil Components in Preclinical Nonalcoholic Fatty Liver Disease Models: A Mechanistic View. Nutrients 2020; 12: 499 
44. Carbone S, Elagizi A, Lavie CJ. Obesity and mortality risk in heart failure: when adipose tissue distribution matters. European Journal of Heart Failure 2018; 20: 1278-1280

45. Streng KW, Voors AA, Hillege HL et al. Waist-to-hip ratio and mortality in heart failure. European Journal of Heart Failure 2018; 20: 1269-1277

46. Ross R, Neeland IJ, Yamashita S et al. Waist circumference as a vital sign in clinical practice: a Consensus Statement from the IAS and ICCR Working Group on Visceral Obesity. Nature reviews Endocrinology 2020; 16: 177-189

47. Schneider HJ, Friedrich $\mathrm{N}$, Klotsche J et al. The predictive value of different measures of obesity for incident cardiovascular events and mortality. The Journal of clinical endocrinology and metabolism 2010; 95: 1777-1785

48. Lechner K, Lechner B, Crispin A et al. Waist-to-height ratio and metabolic phenotype compared to the Matsuda index for the prediction of insulin resistance. Scientific Reports 2021; 11: 8224

49. Da Boit M, Hunter AM, Gray SR. Fit with good fat? The role of $n-3$ polyunsaturated fatty acids on exercise performance. Metabolism: clinical and experimental 2017; 66: 45-54

50. Bobenko A, Bartels I, Munch M et al. Amount or intensity? Potential targets of exercise interventions in patients with heart failure with preserved ejection fraction. ESC heart failure 2018; 5: 53-62

51. Costello-Boerrigter LC, Boerrigter G, Redfield MM et al. Amino-terminal pro-B-type natriuretic peptide and B-type natriuretic peptide in the general community: determinants and detection of left ventricular dysfunction. Journal of the American College of Cardiology 2006; 47: 345-353

52. Massie BM, Carson PE, McMurray JJ et al. Irbesartan in patients with heart failure and preserved ejection fraction. The New England journal of medicine 2008; 359: 2456-2467

53. Grimsgaard S, Bonaa KH, Hansen JB et al. Effects of highly purified eicosapentaenoic acid and docosahexaenoic acid on hemodynamics in humans. The American journal of clinical nutrition 1998; 68: 52-59

54. Oikonomou E, Vogiatzi G, Karlis D et al. Effects of omega-3 polyunsaturated fatty acids on fibrosis, endothelial function and myocardial performance, in ischemic heart failure patients. Clinical nutrition (Edinburgh, Scotland) 2018, DOI: 10.1016/j.clnu.2018.04.017:

55. Edelmann F, Gelbrich G, Dungen HD et al. Exercise training improves exercise capacity and diastolic function in patients with heart failure with preserved ejection fraction: results of the Ex-DHF (Exercise training in Diastolic Heart Failure) pilot study. Journal of the American College of Cardiology 2011; 58: 1780-1791

56. van der Wurff ISM, von Schacky $C$, Bergeland $T$ et al. Exploring the association between whole blood Omega-3 Index, DHA, EPA, DHA, AA and n-6 DPA, and depression and selfesteem in adolescents of lower general secondary education. European journal of nutrition 2019; 58: 1429-1439

57. van der Wurff ISM, von Schacky $C$, Bergeland T et al. Correction to: Exploring the association between whole blood Omega-3 Index, DHA, EPA, DPA, AA and n-6 DPA, and depression and self-esteem in adolescents of lower general secondary education. European journal of nutrition 2020; 59: 843 


\section{Figure Legends}

\section{Central Illustration: Omega-3 Index and HFpEF Patient Characteristics}

Higher O3I was associated with a more favorable cardiometabolic risk profile and submaximal aerobic capacity (left) but did not correlate with echocardiographic markers for left ventricular diastolic function or neurohumoral activation (right). An O3I driven intervention trial might be warranted to answer the question whether O3-FA in therapeutic doses impact on echocardiographic markers for left ventricular diastolic function and neurohumoral activation in patients with HFpEF. This Figure contains modified Images from Servier Medical Art (https://smart.servier.com) licenced by a Creative Commons Attribution 3.0 Unported License.

\section{Omega-3 Index and HFpEF Patient Characteristics}

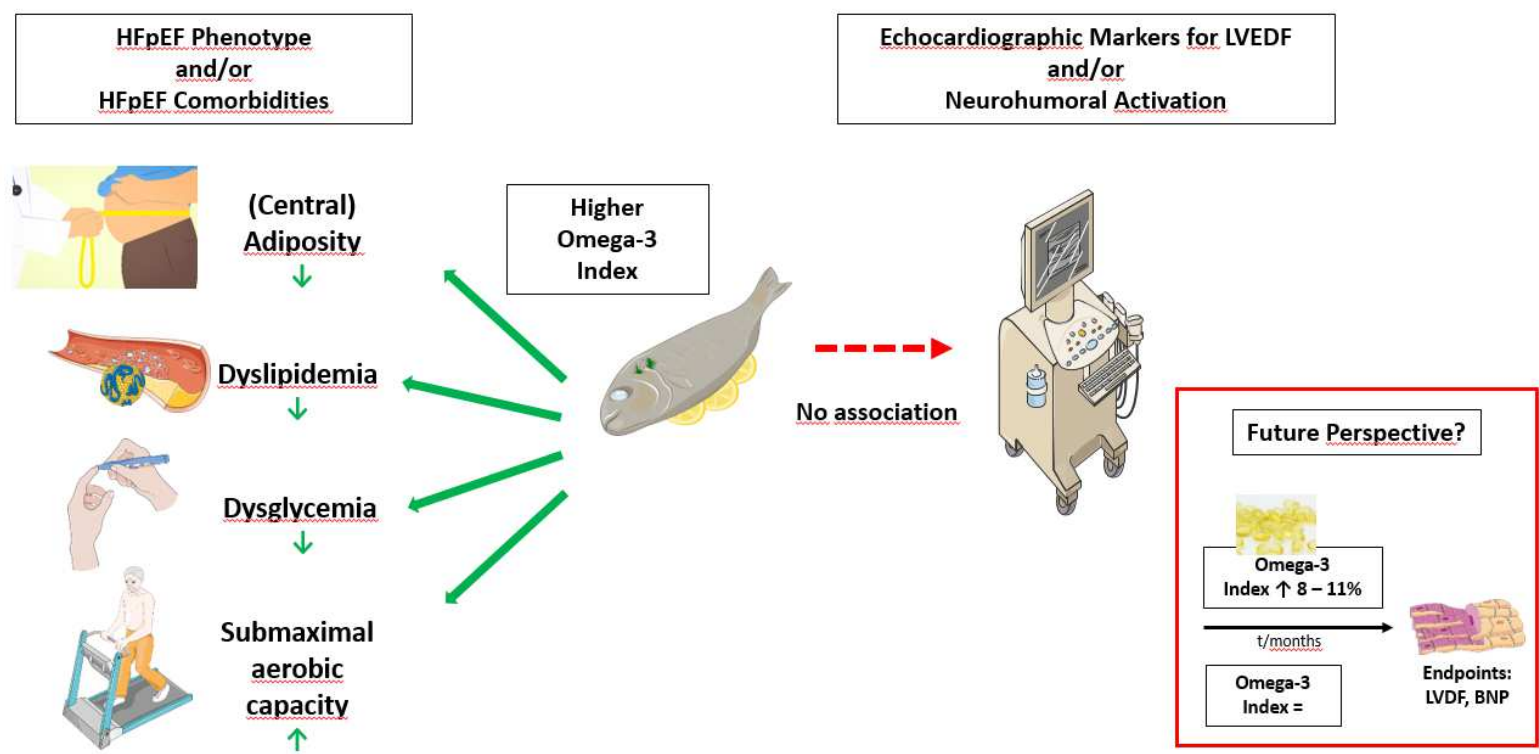


Figure 1: The distribution of the O3I in the Aldo-DHF Cohort

O3I: n 404, mean 5.65\%, SD 1.676, min 2.19\%, max $12.11 \%$

The distribution of the omega-3 index in the Aldo-DHF cohort

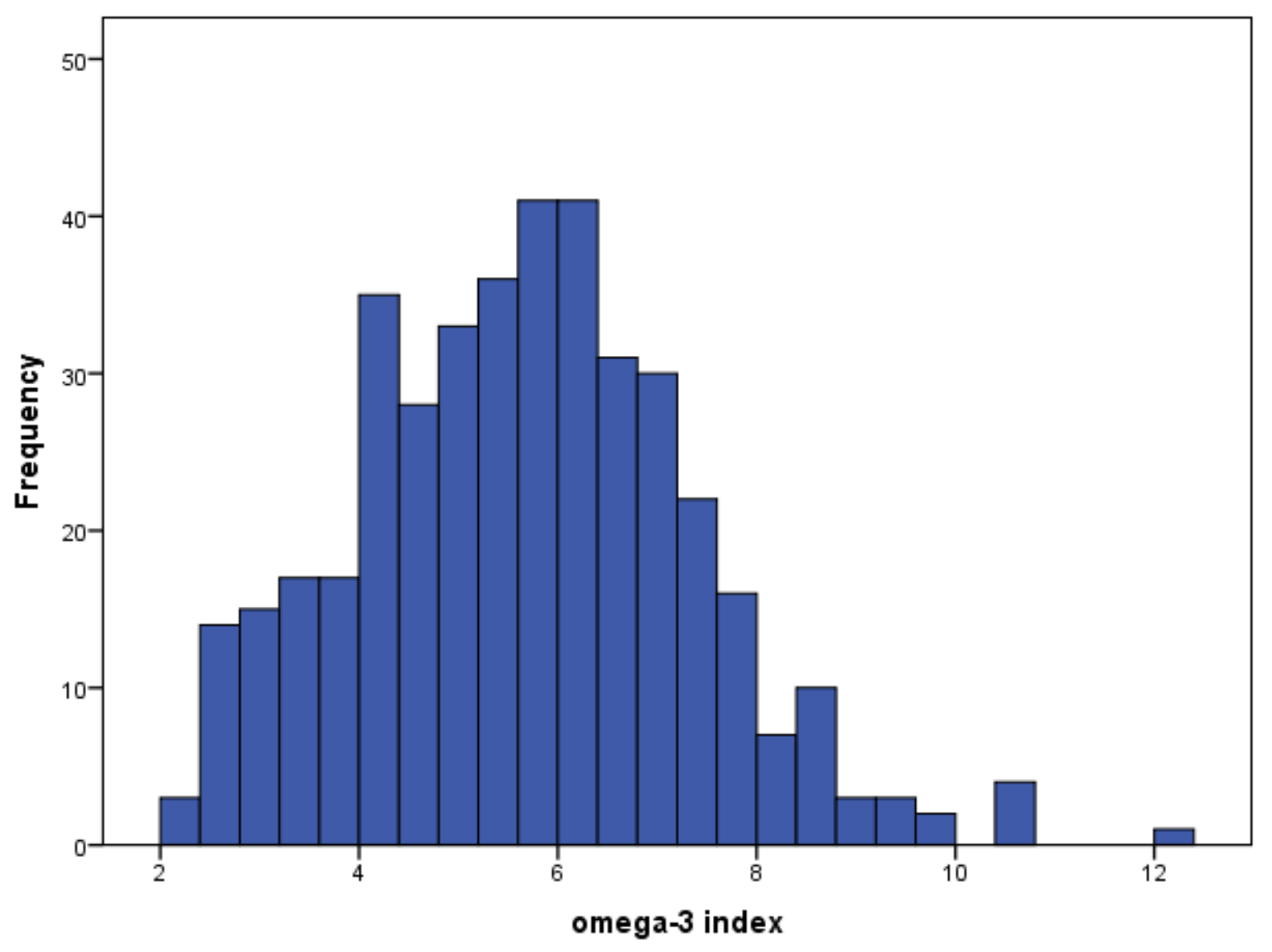


Figure 2: Scatter Plot showing correlations between the O3I and LVEF

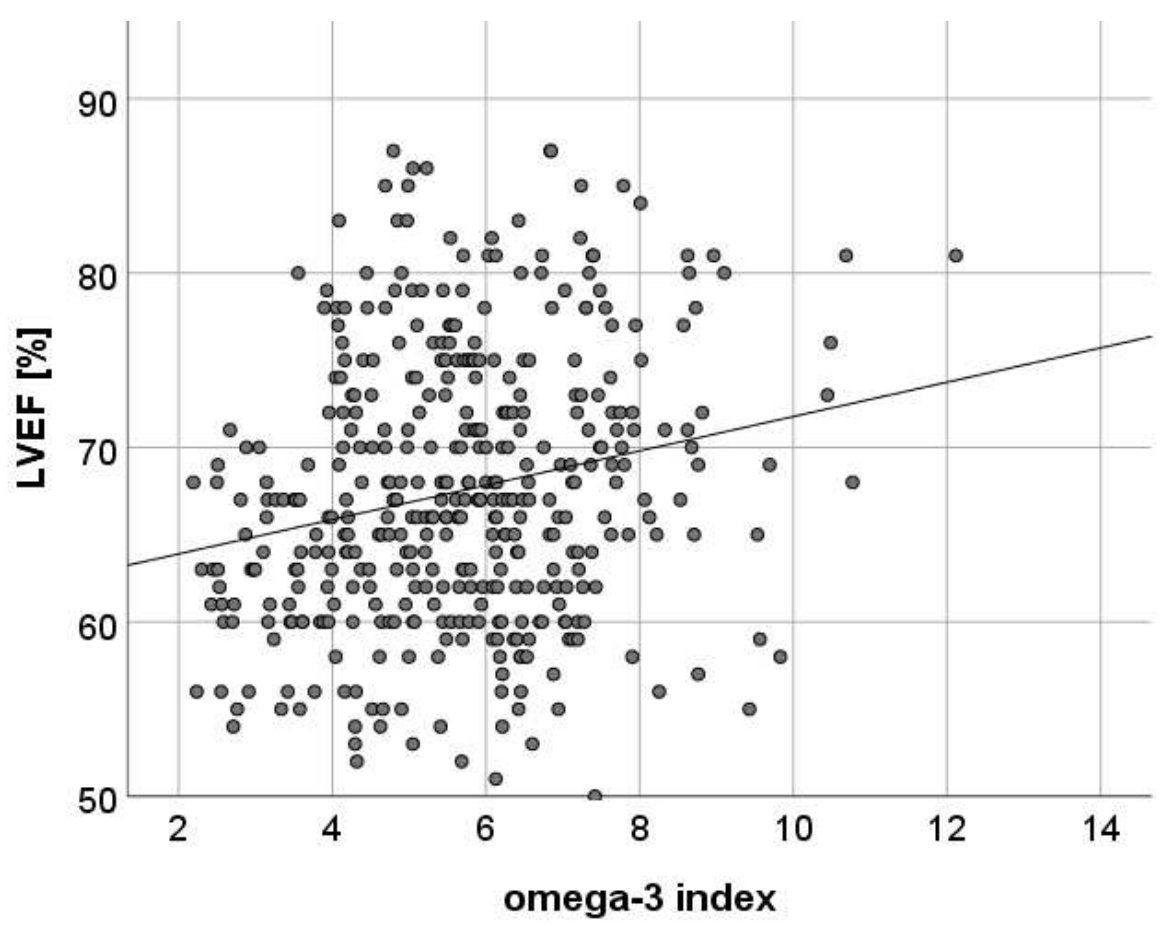

The O3I showed a positive association with LVEF

Multipanel Figure 3: Scatter Plots showing correlations between the O3I and HbA1c (A), TAG/HDL-C ratio (B),

Triglycerides (C), Non-HDL-C (D), Body Mass Index (BMI) (E), WC (F) and Waist-to-height ratio (G)
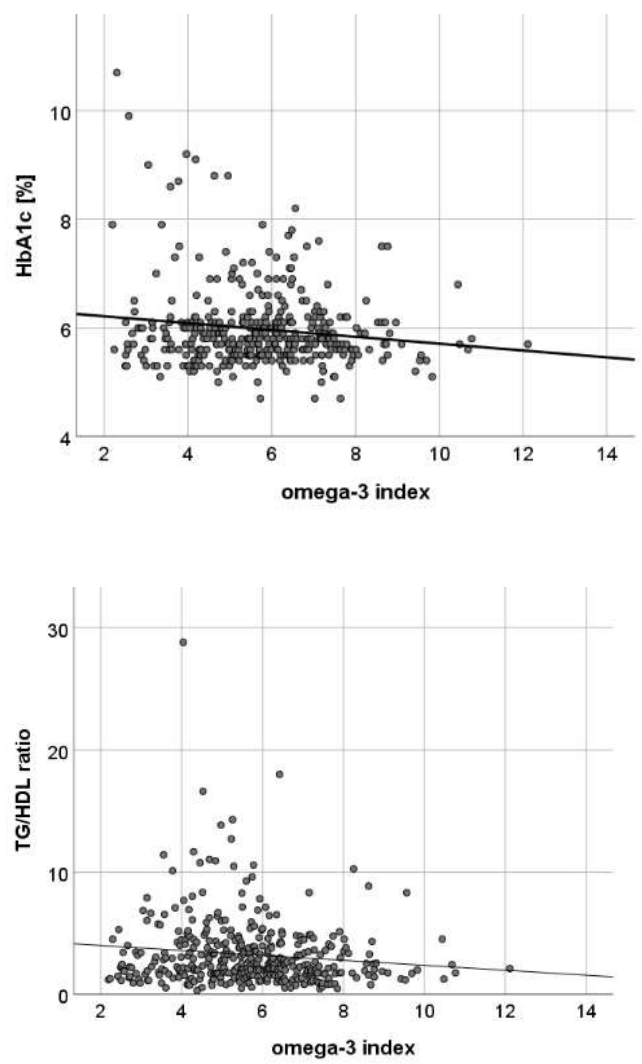

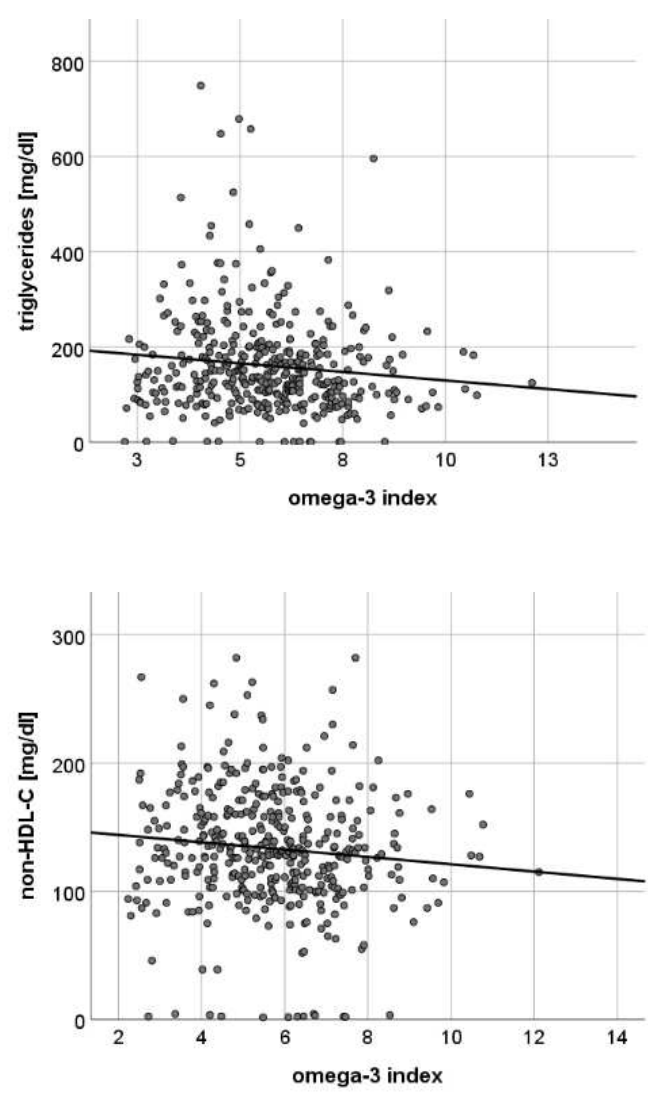

D
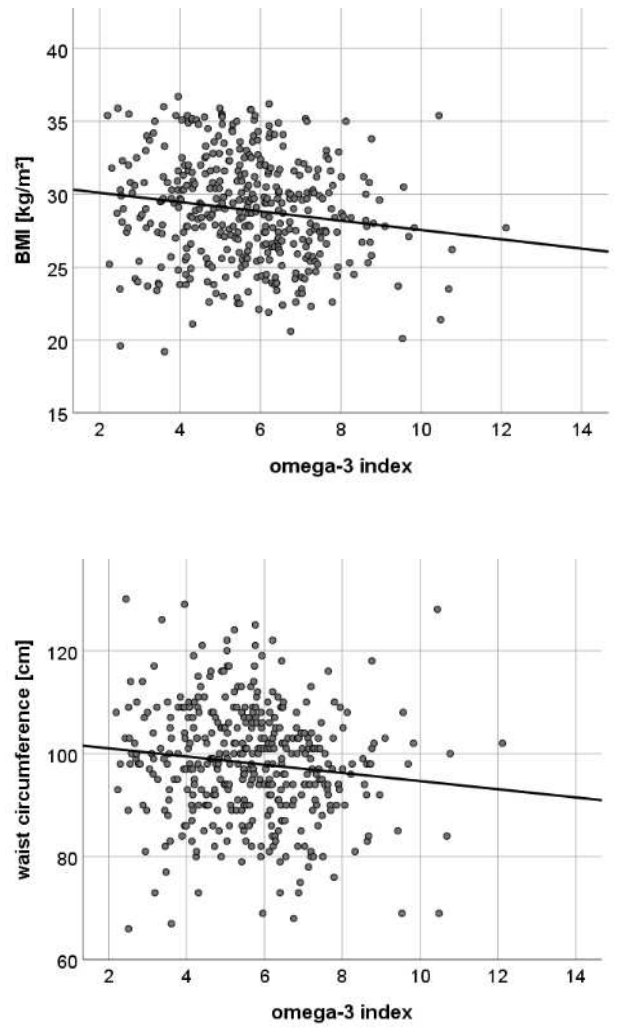


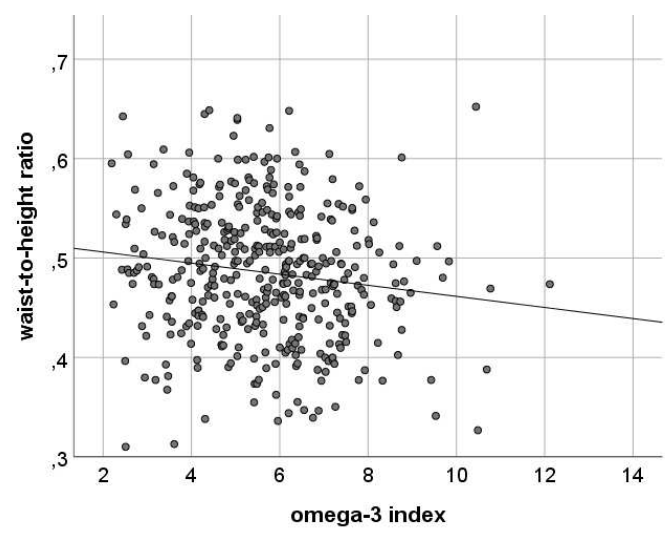

The Omega-3 index was inversely associated with $\mathrm{HbAlc}(\mathrm{A})$, triglycerides-to-HDL-C ratio (TAG/HDL-C ratio) (B), Triglycerides (C), Non-HDL-C (D), Body Mass Index (BMI) (E), Waist Circumference (WC) (F) and WHtR (G)

Multipanel Figure 4: Scatter Plots showing correlations between the O3I and distance covered during the 6 MWT (A) and Maximal Diastolic BP during the 6MWT (B)

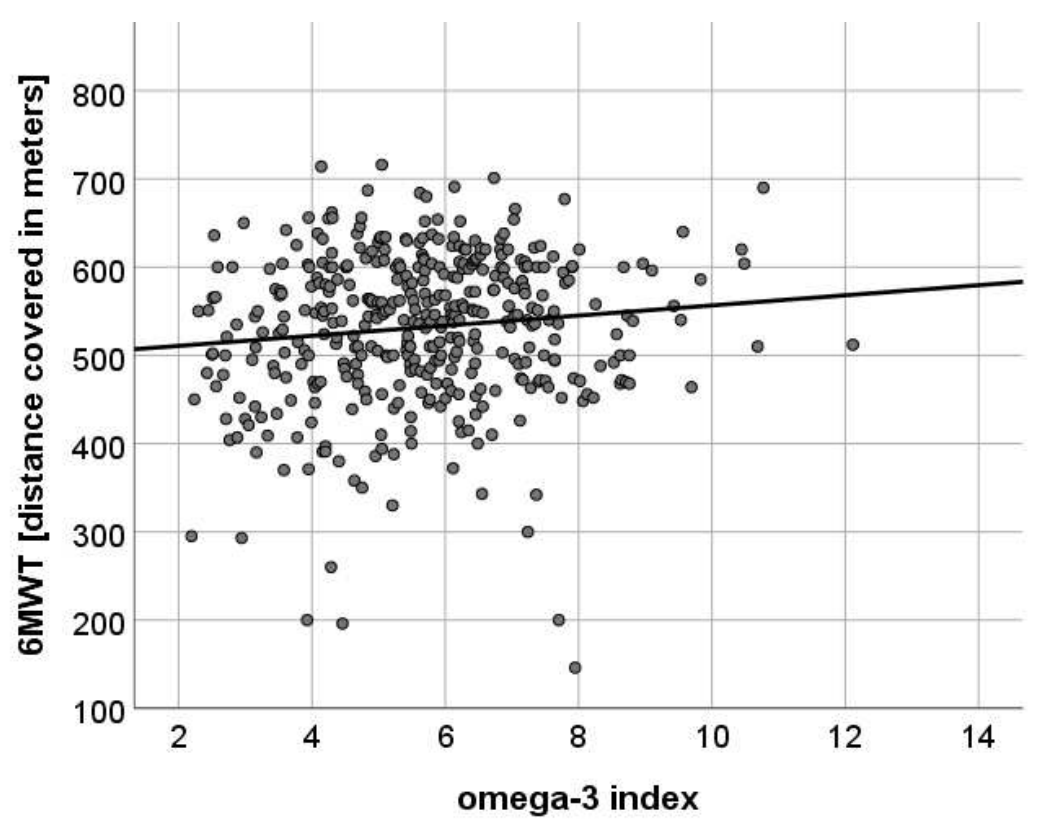




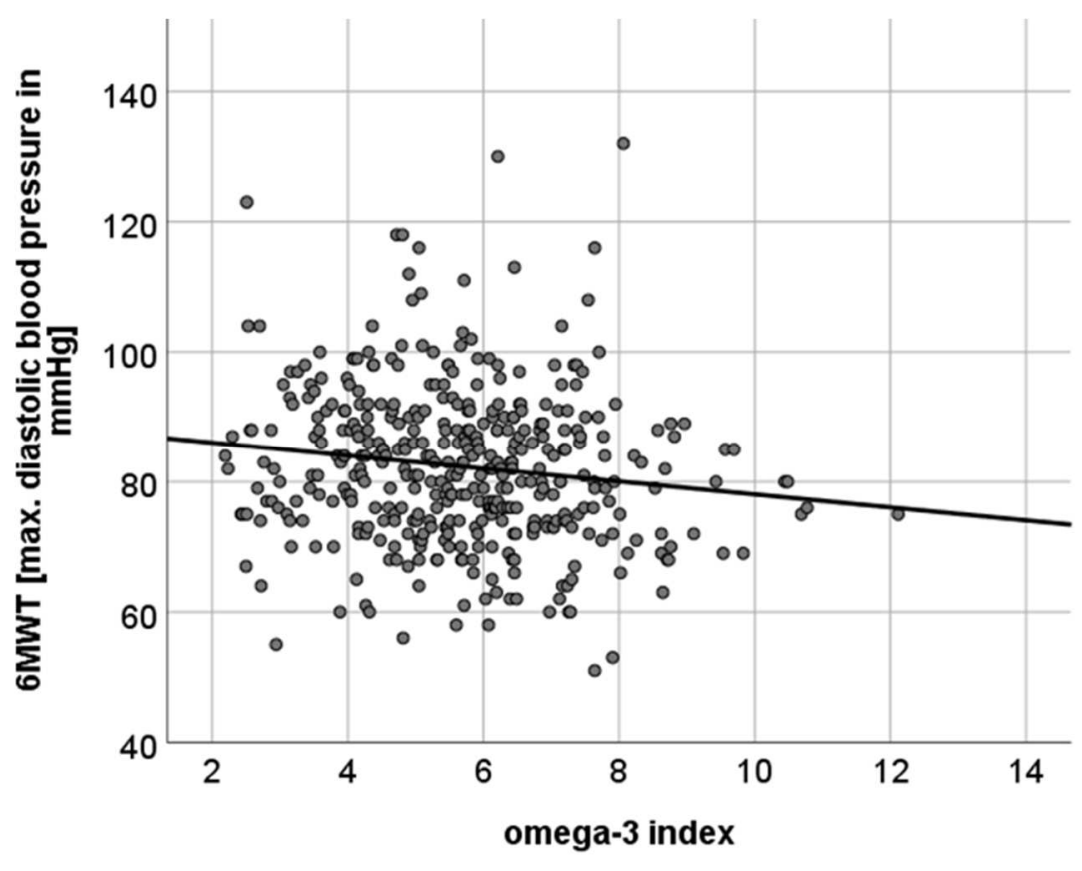

The O3I showed a positive association with submaximal aerobic capacity (A) and was inversely associated with maximal diastolic BP during the 6MWT (B) 


\section{Tables}

Table 1: Baseline Characteristics

\begin{tabular}{|c|c|}
\hline Characteristics $^{\text {a }}$ & $\begin{array}{l}\text { Total } \\
(n=404)\end{array}$ \\
\hline \multicolumn{2}{|l|}{ Demographics } \\
\hline Age, mean (SD), y & $67(8)$ \\
\hline Female & $212(53)$ \\
\hline \multicolumn{2}{|l|}{ Laboratory measures } \\
\hline HbA1c (\%) & $6.0(0.8)$ \\
\hline LDL-C (mg/dl) & $117(42)$ \\
\hline HDL-C (mg/dl) & $56(18)$ \\
\hline Triglyzerides (mg/dl) & $161(103)$ \\
\hline Non-HDL-C (mg/dl) & $133(47)$ \\
\hline TG/HDL-C ratio & $3.3(2.8)$ \\
\hline NT-proBNP, median (IQR), ng/L & $158(82-298)$ \\
\hline Omega-3 Index (\%) & $5.7(1.7)$ \\
\hline \multicolumn{2}{|l|}{ Medical history } \\
\hline${\text { Hospitalization for heart failure in past } 12 \text { months }^{c}}^{c}$ & $149(37)$ \\
\hline Hypertension & $370(92)$ \\
\hline Diabetes mellitus & $66(16)$ \\
\hline Atrial fibrillation & $65(16)$ \\
\hline \multicolumn{2}{|l|}{ Physical examination, mean (SD) } \\
\hline Body mass index ${ }^{b}$ & $28.9(3.6)$ \\
\hline Waist Circumference, $(\mathrm{cm})$ & $98.1(11.0)$ \\
\hline In Men & $103.7(9.0)$ \\
\hline In Women & $93.1(10.3)$ \\
\hline Waist-to-height ratio & $0.49(0.1)$ \\
\hline Systolic blood pressure, $\mathrm{mm} \mathrm{Hg}$ & $135(18)$ \\
\hline Diastolic blood pressure, $\mathrm{mm} \mathrm{Hg}$ & $79(11)$ \\
\hline Heart rate, $/ \mathrm{min}$ & $66(11)$ \\
\hline \multicolumn{2}{|l|}{ Signs and symptoms } \\
\hline NYHA functional class & \\
\hline
\end{tabular}




\begin{tabular}{|c|c|}
\hline II & $350(87)$ \\
\hline III & $54(13)$ \\
\hline Peripheral edema & $160(40)$ \\
\hline Nocturia & $325(80)$ \\
\hline Paroxysmal nocturnal dyspnea & $66(16)$ \\
\hline Nocturnal cough & $61(15)$ \\
\hline Fatigue & $241(60)$ \\
\hline \multicolumn{2}{|l|}{ Current medications } \\
\hline ACE inhibitors/angiotensin receptor antagonists & $310(77)$ \\
\hline Betablockers & $290(72)$ \\
\hline Diuretics & $213(53)$ \\
\hline Calcium antagonists & $97(24)$ \\
\hline Lipid-lowering drugs & $221(55)$ \\
\hline \multicolumn{2}{|l|}{ Echocardiography, mean (SD) } \\
\hline LV ejection fraction, $\%$ & $68(8)$ \\
\hline LV diameter (end diastolic), $\mathrm{mm}$ & $46.5(6.2)$ \\
\hline LV diameter (end systolic), $\mathrm{mm}$ & $25.3(6.4)$ \\
\hline LV mass index, $\mathrm{g} / \mathrm{m} 2$ & $114.15(45.53)$ \\
\hline Left atrial volume index, $\mathrm{mL} / \mathrm{m} 2$ & $43.1(41.6)$ \\
\hline E-wave velocity, $\mathrm{cm} / \mathrm{s}$ & $73(20)$ \\
\hline Medial e' wave velocity, $\mathrm{cm} / \mathrm{s}$ & $5.9(1.3)$ \\
\hline $\mathrm{E} / \mathrm{e}^{\prime}$ & $7.1(1.5)$ \\
\hline E/A velocity ratio & $0.91(0.33)$ \\
\hline Isovolumic relaxation time, $\mathrm{ms}$ & $88(26)$ \\
\hline Deceleration time, $\mathrm{ms}$ & $243(63)$ \\
\hline \multicolumn{2}{|l|}{ Grade of diastolic dysfunction, No. (\%) } \\
\hline I & $295(73)$ \\
\hline II & $81(20)$ \\
\hline III & $4(1)$ \\
\hline IV & $3(1)$ \\
\hline
\end{tabular}

Abbreviations: ACE, angiotensin-converting enzyme; IQR, interquartile range; NT-proBNP, N-terminal pro-braintype natriuretic peptide; NYHA, New York Heart Association; A, peak atrial transmitral ventricular filling velocity; e', early diastolic tissue Doppler velocity; E, peak early transmitral ventricular filling velocity. 
${ }^{a}$ Data are expressed as No. (\%) unless otherwise specified.

body mass index is defined as weight in kilograms divided by height in meter squared.

${ }^{2} 2$ missing from analysis $(n=402)$ 
Table 2 Associations between the O3I/Individual O3-FA, Metabolic Phenotype, and BMI / Anthropometric Markers of Truncal Adiposity

\begin{tabular}{|c|c|c|c|c|c|c|c|c|c|}
\hline \multirow{3}{*}{$\begin{array}{l}\text { ALA } \\
\text { C18:3n3 }\end{array}$} & & $\mathrm{HbA1c}$ & ratio & Triglycerides & C & GGT & {$\left[\mathrm{kg} / \mathrm{m}^{2}\right]$} & WC [cm] & WHtR \\
\hline & Pearson's correlation coefficient & -0.055 & $0.178^{* *}$ & $0.179^{\star *}$ & -0.003 & -0.053 & -0.072 & 0.066 & -0.071 \\
\hline & $p$-value* & 0.277 & 0.000 & 0.000 & 0.955 & 0.293 & 0.148 & 0.185 & 0.152 \\
\hline & $\mathrm{N}$ & 392 & 397 & 399 & 398 & 402 & 404 & 403 & 404 \\
\hline \multirow{3}{*}{$\begin{array}{l}\text { EPA } \\
\text { C20:5n3 }\end{array}$} & Pearson's correlation coefficient & -0.079 & $-0.124^{*}$ & -0.091 & -0.043 & -0.058 & $-0.178^{\star *}$ & $-0.117^{*}$ & $-0.173^{\star \star}$ \\
\hline & p-value* & 0.121 & 0.014 & 0.070 & 0.395 & 0.246 & 0.000 & 0.019 & 0.000 \\
\hline & $\mathrm{N}$ & 392 & 397 & 399 & 398 & 402 & 404 & 403 & 404 \\
\hline \multirow{3}{*}{$\begin{array}{l}\text { DHA } \\
\text { C22:6n3 }\end{array}$} & Pearson's correlation coefficient & $-0.150^{\star *}$ & $-0.107^{*}$ & $-0.116^{*}$ & $-0.115^{*}$ & $-0.140^{\star \star}$ & $-0.124^{*}$ & -0.071 & $-0.115^{*}$ \\
\hline & p-value* & 0.003 & 0.033 & 0.020 & 0.022 & 0.005 & 0.013 & 0.153 & 0.021 \\
\hline & $\mathrm{N}$ & 392 & 397 & 399 & 398 & 402 & 404 & 403 & 404 \\
\hline \multirow{3}{*}{$\begin{array}{l}\text { Omega-3 } \\
\text { Index }\end{array}$} & Pearson's correlation coefficient & $-0.139^{\star \star}$ & $-0.120^{*}$ & $-0.117^{*}$ & $-0.101^{*}$ & $-0.125^{*}$ & $-0.149^{* \star}$ & -0.090 & $-0.141^{\star *}$ \\
\hline & p-value* & 0.006 & 0.017 & 0.020 & 0.044 & 0.012 & 0.003 & 0.070 & 0.005 \\
\hline & $\mathrm{N}$ & 392 & 397 & 399 & 398 & 402 & 404 & 403 & 404 \\
\hline
\end{tabular}

*All tests were performed 2-sided

\begin{tabular}{|c|c|c|c|c|c|c|c|c|}
\hline & & $\begin{array}{l}\text { systolic } \\
\text { blood } \\
\text { pressure }\end{array}$ & $\begin{array}{l}\text { diastolic } \\
\text { blood } \\
\text { pressure }\end{array}$ & heart rate & HDL-C & LDL-C & $\begin{array}{l}\mathrm{ALT} \\
\text { (GPT) }\end{array}$ & $\begin{array}{l}\text { AST } \\
\text { (GOT) }\end{array}$ \\
\hline \multirow[t]{3}{*}{$\begin{array}{l}\text { ALA } \\
\text { C18:3n3 }\end{array}$} & $\begin{array}{l}\text { Pearson's correlation } \\
\text { coefficient }\end{array}$ & 0.014 & $-0.107^{*}$ & 0.011 & $-0.106^{*}$ & -0.020 & $-0.098^{*}$ & -0.042 \\
\hline & $p$-value* & 0.776 & 0.032 & 0.819 & 0.034 & 0.685 & 0.050 & 0.402 \\
\hline & $\mathrm{N}$ & 404 & 404 & 404 & 400 & 393 & 402 & 402 \\
\hline \multirow[t]{3}{*}{$\begin{array}{l}\text { EPA } \\
\text { C20:5n3 }\end{array}$} & $\begin{array}{l}\text { Pearson's correlation } \\
\text { coefficient }\end{array}$ & -0.011 & -0.074 & $-0.109^{*}$ & 0.059 & 0.005 & -0.079 & -0.039 \\
\hline & p-value* & 0.821 & 0.140 & 0.028 & 0.242 & 0.919 & 0.115 & 0.439 \\
\hline & $\mathrm{N}$ & 404 & 404 & 404 & 400 & 393 & 402 & 402 \\
\hline \multirow[t]{3}{*}{$\begin{array}{l}\text { DHA } \\
\text { C22:6n3 }\end{array}$} & $\begin{array}{l}\text { Pearson's correlation } \\
\text { coefficient }\end{array}$ & -0.024 & -0.097 & -0.068 & 0.028 & -0.048 & -0.079 & -0.054 \\
\hline & $p$-value* & 0.633 & 0.052 & 0.175 & 0.582 & 0.344 & 0.115 & 0.282 \\
\hline & $\mathrm{N}$ & 404 & 404 & 404 & 400 & 393 & 402 & 402 \\
\hline \multirow[t]{3}{*}{$\begin{array}{l}\text { Omega-3 } \\
\text { Index }\end{array}$} & $\begin{array}{l}\text { Pearson's correlation } \\
\text { coefficient }\end{array}$ & -0.022 & -0.097 & -0.085 & 0.039 & -0.035 & -0.084 & -0.053 \\
\hline & p-value ${ }^{*}$ & 0.663 & 0.052 & 0.087 & 0.435 & 0.487 & 0.091 & 0.288 \\
\hline & $\mathrm{N}$ & 404 & 404 & 404 & 400 & 393 & 402 & 402 \\
\hline
\end{tabular}

*All tests were performed 2-sided 


\section{Figures}

Figures are provided in TIF format (embedded in ppt) seperately

\section{Supplements}

Supplementary Table 1 Associations between the O3I/Individual O3-FA and LVEF / LV Mass

\begin{tabular}{|c|c|c|c|}
\hline & & LVEF [\%] & LV Mass [g] \\
\hline \multirow[t]{3}{*}{$\begin{array}{l}\text { ALA } \\
\text { C18:3n3 }\end{array}$} & $\begin{array}{l}\text { Pearson's correlation } \\
\text { coefficient }\end{array}$ & 0.007 & 0.021 \\
\hline & p-value ${ }^{*}$ & 0.889 & 0.673 \\
\hline & $\mathrm{N}$ & 404 & 404 \\
\hline \multirow[t]{3}{*}{$\begin{array}{l}\text { EPA } \\
\text { C20:5n3 }\end{array}$} & $\begin{array}{l}\text { Pearson's correlation } \\
\text { coefficient }\end{array}$ & $0.123^{*}$ & -0.007 \\
\hline & p-value* & 0.013 & 0.892 \\
\hline & $\mathrm{N}$ & 404 & 404 \\
\hline \multirow[t]{3}{*}{$\begin{array}{l}\text { DHA } \\
\text { C22:6n3 }\end{array}$} & $\begin{array}{l}\text { Pearson's correlation } \\
\text { coefficient }\end{array}$ & $0.226^{* *}$ & -0.023 \\
\hline & $p$-value* & 0.000 & 0.647 \\
\hline & $\mathrm{N}$ & 404 & 404 \\
\hline \multirow[t]{3}{*}{$\begin{array}{l}\text { Omega-3 } \\
\text { Index }\end{array}$} & $\begin{array}{l}\text { Pearson's correlation } \\
\text { coefficient }\end{array}$ & $0.211^{* *}$ & -0.020 \\
\hline & p-value* & 0.000 & 0.695 \\
\hline & $\mathrm{N}$ & 404 & 404 \\
\hline
\end{tabular}

*All tests were performed 2-sided

Supplementary Table 2 Associations between the O3I/Individual O3-FA and Functional Capacity

\begin{tabular}{|l|r|r|r|r|}
\hline & $\begin{array}{c}\text { distance covered } \\
\text { (meters) }\end{array}$ & $\begin{array}{c}\text { systolic max. } \\
\text { blood } \\
\text { pressure }\end{array}$ & $\begin{array}{c}\text { diastolic } \\
\text { max. blood } \\
\text { pressure }\end{array}$ & peak VO2 \\
\cline { 2 - 6 } & -0.033 & 0.036 & -0.079 & -0.059 \\
\hline Pearson's correlation coefficient $^{\text {p-value* }}$ & 0.508 & 0.473 & 0.113 & 0.234 \\
\hline $\mathrm{N}$ & 403 & 401 & 401 & 404 \\
\hline Pearson's correlation coefficient & 0.097 & 0.026 & -0.084 & 0.081 \\
\hline p-value* & 0.052 & 0.602 & 0.095 & 0.103 \\
\hline N & 403 & 401 & 401 & 404 \\
\hline Pearson's correlation coefficient & $0.109^{*}$ & 0.005 & $-0.147^{* *}$ & -0.039 \\
\hline p-value* & 0.029 & 0.926 & 0.003 & 0.438 \\
\hline N & 403 & 401 & 401 & 404 \\
\hline Pearson's correlation coefficient $^{*}$ & $0.113^{*}$ & 0.012 & $-0.138^{* *}$ & -0.005 \\
\hline p-value* & 0.023 & 0.817 & 0.006 & 0.919 \\
\hline N & 403 & 401 & 401 & 404 \\
\hline
\end{tabular}

*All tests were performed 2-sided 
Supplementary Table 3 Associations between the O3I/Individual O3-FA and echocardiographic parameters of LVDF/neurohumoral activation. The association of the O3I and NT-proBNP was calculated using logarithmic transformation (base-10 logarithm) for NT-proBNP. The numbers of patients available for every variable is indicated.

\begin{tabular}{|c|c|c|c|c|c|c|c|c|c|c|}
\hline & & $\mathrm{E} / \mathrm{A}$ & $\begin{array}{l}\text { deceleration } \\
\text { time }[\mathrm{ms}]\end{array}$ & $E / e^{\prime}$ & $\begin{array}{l}\text { Tissue-Doppler: } \\
\text { e'lateral [cm/s] }\end{array}$ & $\begin{array}{l}\text { Tissue-Doppler: } \\
\text { e'medial [cm/s] }\end{array}$ & $\begin{array}{c}\text { LA-Area } \\
4 \mathrm{CH}\end{array}$ & $\begin{array}{c}\text { LA-Area } \\
2 \mathrm{CH}\end{array}$ & LAVI & $\begin{array}{c}\text { NT- } \\
\text { proBNP } \\
(\mathrm{pg} / \mathrm{ml})\end{array}$ \\
\hline \multirow[t]{3}{*}{$\begin{array}{l}\text { ALA } \\
\text { C18:3n3 }\end{array}$} & $\begin{array}{l}\text { Pearson's } \\
\text { correlation } \\
\text { coefficient }\end{array}$ & 0.022 & -0.022 & 0.045 & 0.070 & -0.004 & 0.020 & 0.038 & -0.002 & $0.184^{* *}$ \\
\hline & p-value* & 0.660 & 0.664 & 0.366 & 0.160 & 0.930 & 0.683 & 0.456 & 0.967 & 0.000 \\
\hline & $\mathrm{N}$ & 387 & 404 & 403 & 401 & 404 & 401 & 392 & 391 & 392 \\
\hline \multirow[t]{3}{*}{$\begin{array}{l}\text { EPA } \\
\text { C20:5n3 }\end{array}$} & $\begin{array}{l}\text { Pearson's } \\
\text { correlation } \\
\text { coefficient }\end{array}$ & 0.011 & -0.033 & $-0,051$ & $-0,029$ & -0.071 & -0.026 & 0.003 & -0.027 & 0.096 \\
\hline & $p$-value* & 0.835 & 0.509 & 0.303 & 0.564 & 0.155 & 0.607 & 0.959 & 0.596 & 0.057 \\
\hline & $\mathrm{N}$ & 387 & 404 & 403 & 401 & 404 & 401 & 392 & 391 & 392 \\
\hline \multirow[t]{3}{*}{$\begin{array}{l}\text { DHA } \\
\text { C22:6n3 }\end{array}$} & $\begin{array}{l}\text { Pearson's } \\
\text { correlation } \\
\text { coefficient }\end{array}$ & -0.044 & 0.038 & $-0,017$ & 0.008 & -0.055 & -0.060 & 0.018 & -0.027 & 0.042 \\
\hline & $p$-value ${ }^{*}$ & 0.389 & 0.448 & 0.727 & 0.878 & 0.269 & 0.229 & 0.715 & 0.598 & 0.407 \\
\hline & $\mathrm{N}$ & 387 & 404 & 403 & 401 & 404 & 401 & 392 & 391 & 392 \\
\hline \multirow[t]{3}{*}{$\begin{array}{l}\text { Omega- } \\
3 \text { Index }\end{array}$} & $\begin{array}{l}\text { Pearson's } \\
\text { correlation } \\
\text { coefficient }\end{array}$ & -0.031 & 0.019 & -0.029 & -0.003 & -0.064 & -0.054 & 0.015 & -0.029 & 0.062 \\
\hline & $p$-value* & 0.550 & 0.703 & 0.561 & 0.953 & 0.200 & 0.280 & 0.767 & 0.571 & 0.221 \\
\hline & $\mathrm{N}$ & 387 & 404 & 403 & 401 & 404 & 401 & 392 & 391 & 392 \\
\hline
\end{tabular}

*All tests were performed 2-sided 
Figures

The distribution of the omega-3 index in the Aldo-DHF cohort

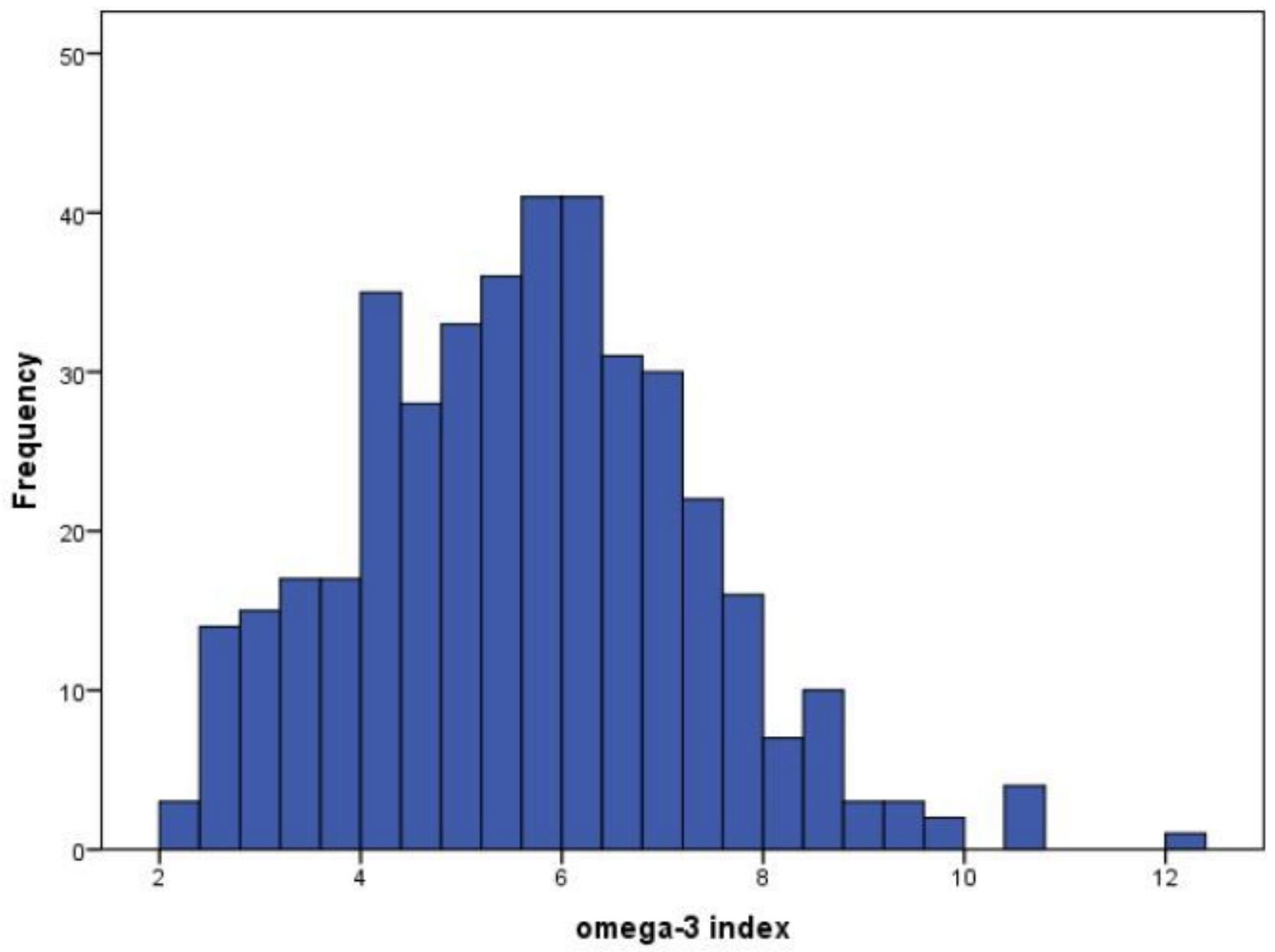

Figure 1

The distribution of the O3I in the Aldo-DHF Cohort O3I: $\mathrm{n} 404$, mean $5.65 \%$, SD 1.676, min $2.19 \%$, max $12.11 \%$ 


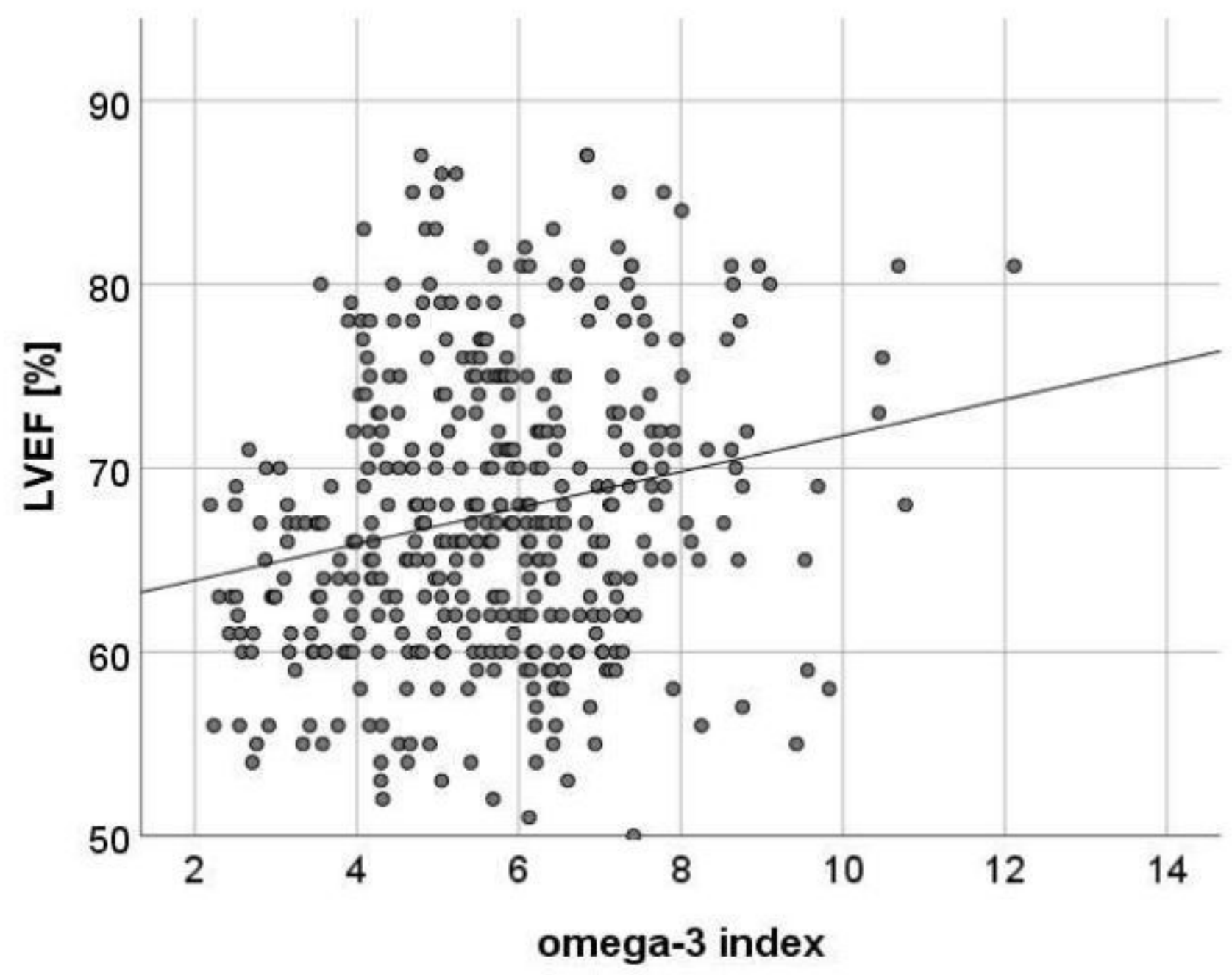

Figure 2

Scatter Plot showing correlations between the O3I and LVEF
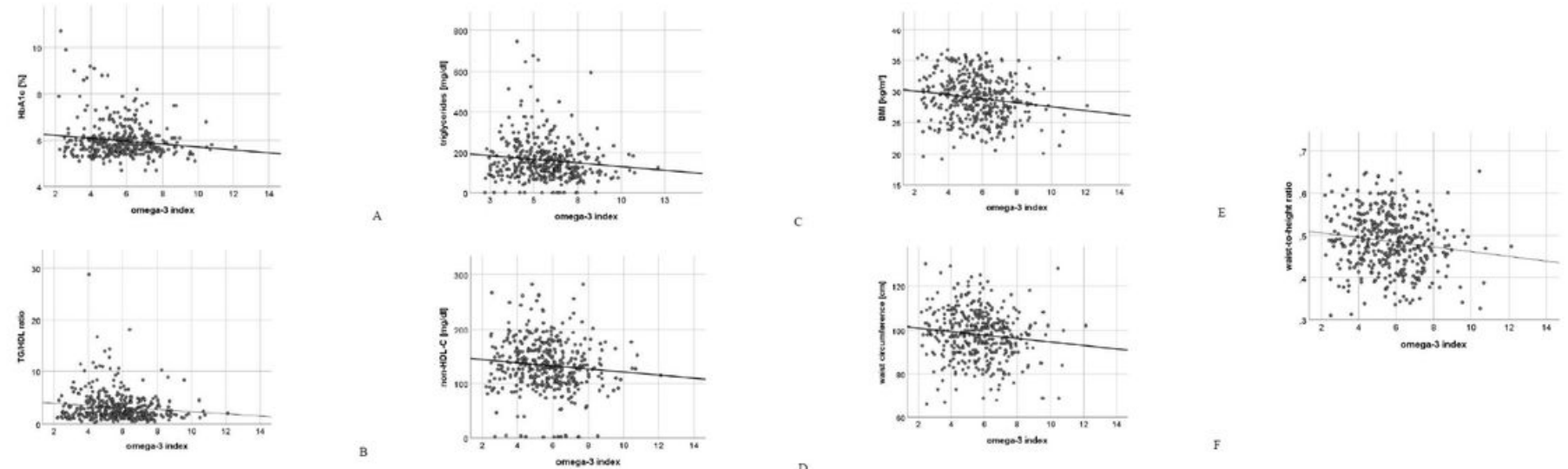

Figure 3 
Scatter Plots showing correlations between the $03 \mathrm{I}$ and $\mathrm{HbA1c}(\mathrm{A}), \mathrm{TAG} / \mathrm{HDL}-\mathrm{C}$ ratio (B), Triglycerides (C), Non-HDL-C (D), Body Mass Index (BMI) (E), WC (F) and Waist-to-height ratio (G)
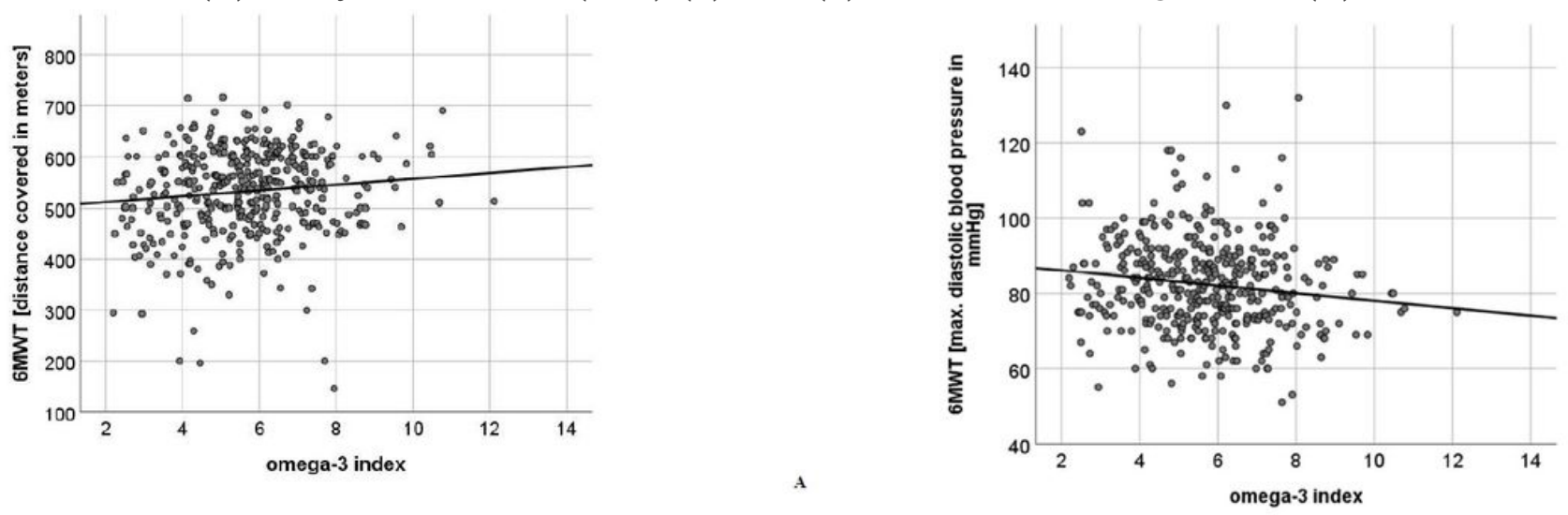

\section{Figure 4}

Scatter Plots showing correlations between the $03 \mathrm{I}$ and distance covered during the 6 MWT (A) and Maximal Diastolic BP during the 6MWT (B) 